\title{
Identification of the Compounds Responsible for the Sweat-Like Odor in Hop (Humulus lupulus L.) Volatile Oil
}

\author{
Hironari Miyazato ${ }^{1}$ \\ ${ }^{1}$ Research and Development Center, Nagaoka Perfumery Co., Ltd., Osaka, Japan \\ Correspondence: Hironari Miyazato, Research and Development Center, Nagaoka Perfumery Co., Ltd., 1-3-30 \\ Itsukaichi, Ibaraki, Osaka 567-0005, Japan. E-mail: hironari-miyazato@npc-nagaoka.co.jp
}

Received: June 25, 2013 Accepted: July 25, 2013 Online Published: August 6, 2013

doi:10.5539/jfr.v2n5p34 URL: http://dx.doi.org/10.5539/jfr.v2n5p34

\begin{abstract}
The aroma of hop volatile oil contains a sweat-like odor. We studied the odorous volatile compounds responsible for the sweat-like odor in the volatile oil extracted from Hallertau Perle hop (Humulus lupulus L.) pellets. The combined use of gas chromatography-mass spectrometry/olfactometry (GC-MS/O), aroma extract dilution analysis (AEDA) by GC-MS/O (an odor dilution technique), and heart-cut multidimensional GC-MS (heart-cut MDGC-MS) equipped with the polar (1D) and apolar (2D) capillary columns revealed seven sweat-like odor producing compounds: methyl-branched saturated and unsaturated aliphatic acids, such as 3-methylbutanoic acid (sweaty/rancid/cheese-like), 2-methylbutanoic acid (sweaty/rancid/cheese-like), 4-methyl-3-pentenoic acid (sweaty/urine-like/malodor in laundry), and (E)-4-methyl-3-hexenoic acid (sweaty/urine-like/malodor in laundry), as well as others, such as an unknown compound (sweaty), methyl (E)-4-methyl-3-hexenoate (sweaty/malodor in laundry/fruity), and $S$-methyl (E)-4-methyl-3-hexenethioate (sweaty/rubber). The reference substances were synthesized stereoselectively using for the identification procedures. In this study, (E)-4-methyl-3-hexenoic acid, methyl (E)-4-methyl-3-hexenoate, and $S$-methyl $(E)$-4-methyl-3-hexenethioate were identified for the first time in hop volatile oil.
\end{abstract}

Keywords: hop (Humulus lupulus L.), sweaty odor, gas chromatography-mass spectrometry/olfactometry (GC-MS/O), aroma extract dilution analysis (AEDA), multidimensional gas chromatography-mass spectrometry (MDGC-MS), organic synthesis

Abbreviations: AEDA: aroma extract dilution analysis; 1D: first dimension; 2D: second dimension; FID: flame ionization detector; FD: flavor dilution; FPD: flame photometric detector; GC: gas chromatography; GC-MS/O: gas chromatography-mass spectrometry/olfactometry; GC-O: gas chromatography-olfactometry; heart-cut MDGC-MS: heart-cut multidimensional gas chromatography-mass spectrometry; IR: Infrared; NMR: nuclear magnetic resonance; RI: retention index; ${ }^{\mathrm{t}} \mathrm{R}$ : retention time.

\section{Introduction}

Hop (Humulu slupulus L.) is essential material for beer production along with water, malted barley, and yeast, which act the characteristic hop aroma and bitter taste. To date, 429 distinct hop volatiles have been reported (Nijssen, Ingen-Visscher, \& Donders, 2013). The odor-active compounds contributing to the overall aroma of hops have been found by means of aroma extract dilution analysis (AEDA) (Ullrich \& Grosch, 1987), an odor dilution technique for screening using gas chromatography-olfactometry (GC-O) (Steinhaus \& Schieberle, 2000; Lermusieau, Bulens, \& Collin, 2001; Steinhaus, Wilhelm, \& Schieberle, 2007). Steinhaus and Schieberle (2000) determined 38 and 31 odor-active compounds of fresh and dried hop cones (Spalter Select), respectively. Lermusieau et al. (2001) reported 56 odor-active components in fresh hop pellets (Challenger and Saaz). Later, Steinhaus et al. (2007) characterized 38 odor-active compounds in five different hop varieties (Hallertau Perle, Hallertau Hersbrucker Spät, Slowenian Golding, Hallertau Smaragd, and US Cascade). In addition, by another dilution technique, many odor-active compounds have been identified in hops (Eyres \& Dufour, 2009); however, not all odorous compounds of hops have been identified.

The hop aroma contains a sweat-like odor (Furukawa, Murakami, \& Ichii, 2012). Other than brief descriptions (Steinhaus \& Schieberle, 2000; Lermusieau et al., 2001; Steinhaus et al., 2007), there are no detailed reports regarding the aroma components responsible for the sweat-like odor in hops, most of which may contribute to the overall aroma. Based on our previous study (Miyazato, Hashimoto, \& Hayashi, 2013), we predict that the 
sweat-like odor perceived in hop volatile oil might be associated with volatile carboxylic acids.

The focus of this study is on the novel sweat-like-odor active compounds in Hallertau Perlehop volatile oil. The oil was extracted from the pelletized hop by simultaneous steam distillation-extraction. In order to concentrate the extracted hop oil, the following three procedures were conducted: chemical treatment by an alkaline solution to separate the acidic and neutral/basic volatile fractions, fractionation by silica gel column chromatography, and separation by preparative GC. The concentrated volatile fractions were analyzed by gas chromatography-mass spectrometry/olfactometry (GC-MS/O), AEDA, and heart-cut multidimensional gas chromatography-mass spectrometry (heart-cut MDGC-MS) to identify target active compounds with a sweat-like odor by comparison with synthesized reference substances.

\section{Materials and Methods}

\subsection{Materials}

Hallertau Perle hop pellets (product name: Hallertau Perle Pellets 90) were cultivated in Germany in 2007. The sample was encased in a hermetic dark package and stored at $-15{ }^{\circ} \mathrm{C}$ prior to use.

\subsection{Chemicals}

4-Methyl-3-pentenoic acid was synthesized according to the literature (Mikolajczak \& Smith Jr., 1978). (E)-4-Methyl-3-hexenoic acid was synthesized stereoselectively in two steps, according to the literature (Miyazato et al., 2013). Methyl (E)-4-methyl-3-hexenoate was synthesized via boron trifluoride-catalyzed methyl esterification of $(E)$-4-methyl-3-hexenoic acid starting from $(E)$-4-methyl-3-hexen-1-ol. $S$-Methyl $(E)$-4-methyl-3-hexenethioate was synthesized via the direct thioesterification of (E)-4-methyl-3-hexenoic acid with methyl chlorothiolformate according to the literature (Khan et al., 1999), starting from (E)-4-methyl-3-hexen-1-ol.

The starting substances for the ester or thioester synthesis were commercially available. Boron trifluoride-methanol solution (14\%) and methyl chlorothiolformate were purchased from Sigma Aldrich Japan (Tokyo, Japan). tert-Butyl methyl ether, dichloromethane, 4-dimethylaminopyridine, and sodium chloride were purchased from Wako Pure Chemical Industries (Osaka, Japan). Acetone, pentane, 2-propanol, hexane, ethyl acetate, diethyl ether, hydrochloric acid (35\%), triethylamine, sodium hydrogen carbonate, anhydrous sodium sulfate, anhydrous magnesium sulfate, and silica gel (Ultra Pure Silica Gel 230-400 mesh, SiliCycle Inc., Quebec City, Canada) were purchased from Nacalai Tesque (Kyoto, Japan). Jones reagent was prepared according to the literature (Miyazato et al., 2013).

\subsection{Syntheses}

\subsubsection{Methyl (E)-4-methyl-3-hexenoate}

(E)-4-Methyl-3-hexen-1-ol (300 mg) was dissolved in acetone $(25 \mathrm{~mL})$ at $0{ }^{\circ} \mathrm{C}$. The Jones reagent $(400 \mu \mathrm{L})$ was added to the solution and the mixture was stirred at $0{ }^{\circ} \mathrm{C}$ for $5 \mathrm{~min}$. 2-Propanol $(300 \mu \mathrm{L})$ and sodium hydrogen carbonate $(150 \mathrm{mg}$ ) was added and then the mixture was filtered by a filter paper (Grade No.2, ADVANTEC, Tokyo, Japan). The organic phase was dried over anhydrous magnesium sulfate, filtered by a filter paper, and then concentrated using a rotary evaporator Rotavapor R-200 (Nihon Büchi K.K., Tokyo, Japan)(30 mmHg, $\left.40{ }^{\circ} \mathrm{C}\right)$ to give a green product, which was mixed with boron trifluoride-methanol $(2 \mathrm{~mL})$ and then heated at $100{ }^{\circ} \mathrm{C}$ for $2 \mathrm{~min}$. After cooling at room temperature, the mixture was shaken with brine $(4 \mathrm{~mL})$ for $2 \mathrm{~min}$. The aqueous phase was extracted with pentane $(1 \times 10 \mathrm{~mL})$. The organic phase was dried over anhydrous magnesium sulfate, filtered by a filter paper, and then concentrated using a rotary evaporator $\left(760 \mathrm{mmHg}, 40{ }^{\circ} \mathrm{C}\right)$ to afford a crude product, which was then purified by flash column chromatography on silica gel (hexane/ethyl acetate $=$ $98 / 2, \mathrm{v} / \mathrm{v})$ to give methyl $(E)-4$-methyl-3-hexenoate (110 mg; impurities: $19 \%$ by GC), which was further purified by preparative GC under the conditions shown in Table 1 . Final purification level was $87 \%$ by GC. The spectral data except for mass spectrum are shown below.

IR (neat, $\mathrm{cm}^{-1}$ ): $2966 \mathrm{~m}, 1743 \mathrm{~s}, 1436 \mathrm{~m}, 1365 \mathrm{w}, 1314 \mathrm{w}, 1259 \mathrm{w}, 1199 \mathrm{w}, 1160 \mathrm{~m}, 1110 \mathrm{w}, 1016 \mathrm{~m}, 836 \mathrm{w}$. ${ }^{1} \mathrm{HNMR}\left(401.3 \mathrm{MHz}, \mathrm{CDCl}_{3}, \delta \mathrm{ppm}\right): 5.30\left(1 \mathrm{H}, \mathrm{t}, J=7.4 \mathrm{~Hz}, \mathrm{C}=\mathrm{C}_{\underline{H}} \mathrm{CH}_{2}\right), 3.68\left(3 \mathrm{H}, \mathrm{s}, \mathrm{OC}_{\underline{H}}\right), 3.05(2 \mathrm{H}, \mathrm{d}, J=$ $\left.6.9 \mathrm{~Hz},=\mathrm{CHC}_{2} \mathrm{C}=\mathrm{O}\right), 2.03\left(2 \mathrm{H}, \mathrm{q}, J=7.4 \mathrm{~Hz}, \mathrm{CH}_{3} \underline{\mathrm{C}}_{2} \mathrm{C}=\right), 1.63\left(3 \mathrm{H}, \mathrm{s}, \underline{\mathrm{C}}_{3} \mathrm{C}=\right), 1.00(3 \mathrm{H}, \mathrm{t}, J=7.4 \mathrm{~Hz}$, $\left.\mathrm{C}_{3} \mathrm{CH}_{2}\right) .{ }^{13} \mathrm{C}$ NMR $\left(100.9 \mathrm{MHz}, \mathrm{CDCl}_{3}, \delta \mathrm{ppm}\right): 173.19\left(\mathrm{COOCH}_{3}\right), 141.06(=\underline{\mathrm{C}}=), 114.37\left(=\underline{\mathrm{CHCH}}_{2}\right), 51.88$ $\left(\mathrm{OCH}_{3}\right), 33.66\left(\mathrm{CHCH}_{2} \mathrm{COOCH}_{3}\right), 32.37\left(\mathrm{CH}_{3} \underline{\mathrm{CH}}_{2} \mathrm{C}=\right), 16.39\left(\underline{\mathrm{CH}}_{3} \mathrm{C}=\right), 12.60\left(\underline{\mathrm{CH}}_{3} \mathrm{CH}_{2}\right)$.

\subsubsection{S-Methyl (E)-4-methyl-3-hexenethioate}

The crude product containing the corresponding acid, obtained from $(E)$-4-methyl-3-hexen-1-ol (300 mg) in the same manner as the above ester synthesis, was mixed with 4-dimethylaminopyridine $(1.4 \mathrm{mg})$ and triethylamine 
$(2 \mathrm{~mL})$ in dichloromethane $(60 \mathrm{~mL})$. After cooling at $0{ }^{\circ} \mathrm{C}$, methyl chlorothiolformate $(480 \mu \mathrm{L})$ was added and the mixture was stirred at $0{ }^{\circ} \mathrm{C}$ for $1 \mathrm{~h}$ followed by incubating at room temperature for $4 \mathrm{~h}$. After adding $1 \mathrm{~N}$ hydrochloric acid $(20 \mathrm{~mL})$, the mixture was extracted with tert-butyl methyl ether $(3 \times 50 \mathrm{~mL})$. The combined organic phases were washed with saturated sodium hydrogen carbonate solution $(3 \times 20 \mathrm{~mL})$ and brine $(3 \times 20$ $\mathrm{mL}$ ), dried over anhydrous magnesium sulfate, filtered via the filter paper, and then concentrated using a rotary evaporator $\left(30 \mathrm{mmHg}, 40{ }^{\circ} \mathrm{C}\right)$ to afford a crude product, which was then purified by flash column chromatography on silica gel (hexane/ethyl acetate $=98 / 2$, v/v) to give $S$-methyl $(E$ )-4-methyl-3-hexenethioate (157 mg; impurities: $80 \%$ by GC), which was further purified by preparative GC under the conditions shown in Table 1. Final purification level was $66 \%$ by GC. The spectral data except for mass spectrum are shown below.

IR (neat, $\mathrm{cm}^{-1}$ ): 2965 m, 2929 m, 1693 s, 1656 m, 1408 w, 1379 w, 1249 w, 1102 m, 1071 m, 1016 m, 854 w. ${ }^{1} \mathrm{H}$ $\operatorname{NMR}\left(401.3 \mathrm{MHz}, \mathrm{CDCl}_{3}, \delta \mathrm{ppm}\right): 5.30\left(1 \mathrm{H}, \mathrm{dt}, J=1.4,7.4 \mathrm{~Hz}, \mathrm{C}=\mathrm{CHCH}_{2}\right), 3.26(2 \mathrm{H}, \mathrm{d}, J=7.4 \mathrm{~Hz}$, $\left.=\mathrm{CHC}_{2} \mathrm{C}=\mathrm{O}\right), 2.27\left(3 \mathrm{H}, \mathrm{s}, \mathrm{SC}_{3}\right), 2.06\left(2 \mathrm{H}, \mathrm{q}, J=7.4 \mathrm{~Hz}, \mathrm{CH}_{3} \underline{\mathrm{C}}_{2} \mathrm{C}=\right), 1.66\left(3 \mathrm{H}, \mathrm{s}, \mathrm{C}_{3} \mathrm{C}=\right), 1.02(3 \mathrm{H}, \mathrm{t}, J=$ $\left.7.4 \mathrm{~Hz}, \mathrm{CH}_{3} \mathrm{CH}_{2}\right) .{ }^{13} \mathrm{C}$ NMR $\left.\left(100.9 \mathrm{MHz}, \mathrm{CDCl}_{3}, \delta \mathrm{ppm}\right): 199.31(\underline{\mathrm{C}}=\mathrm{O}) \mathrm{SCH}_{3}\right), 142.81 \quad(=\mathrm{C}=), 114.12$ $\left(=\underline{\mathrm{CHCH}_{2}}\right), 43.28\left(=\mathrm{CH} \underline{\mathrm{C}} \mathrm{H}_{2} \mathrm{C}(=\mathrm{O})\right), 32.47\left(\mathrm{CH}_{3} \underline{\mathrm{CH}}_{2} \mathrm{C}=\right), 16.50\left(\underline{\mathrm{CH}}_{3} \mathrm{C}=\right), 12.51\left(\underline{\mathrm{CH}}_{3} \mathrm{CH}_{2}\right), 11.82\left(\mathrm{~S}^{\mathrm{C}} \mathrm{H}_{3}\right)$.

\subsection{Methods}

The sample preparation is summarized in a flowchart (Figure 1).

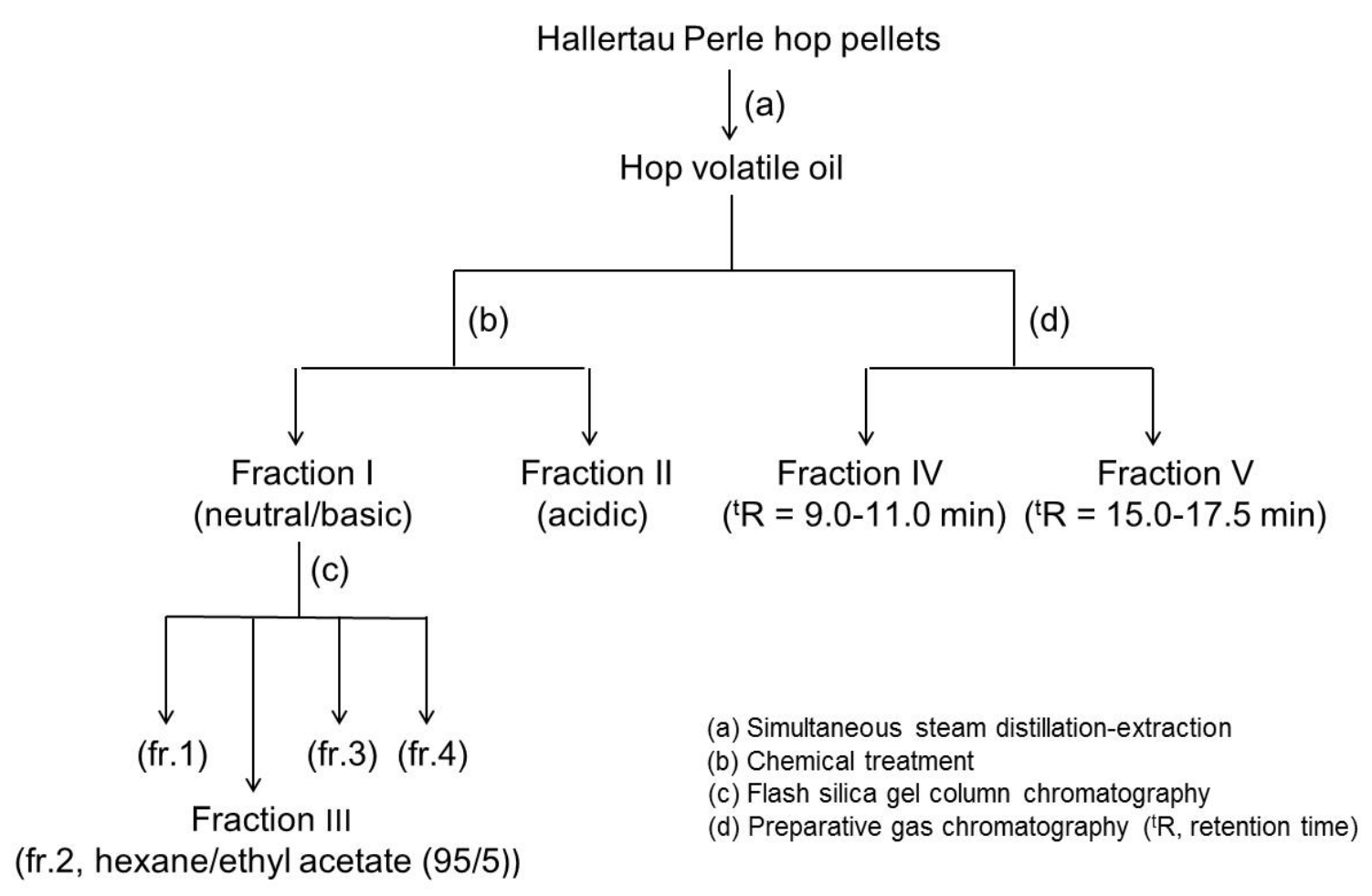

Figure 1. Sample preparation flowchart

\subsubsection{Isolation of the Hop Volatile Oil}

The hop pellet (100.6 g) oil extraction was performed using simultaneous steam distillation-extraction with a Likens-Nickerson extractor (Likens \& Nickerson, 1964) and diethyl ether $(200 \mathrm{~mL})$ for $1.5 \mathrm{~h}$. The extract was dried over anhydrous sodium sulfate, filtered via the filter paper, and then concentrated using a rotary evaporator (760 $\mathrm{mm} \mathrm{Hg}, 40^{\circ} \mathrm{C}$ ) to produce the hop volatile oil $(\sim 1.2 \mathrm{~g})$.

\subsubsection{Separation of Acidic and Neutral/Basic Fractions by Chemical Treatment}

The hop volatile oil $(1.01 \mathrm{~g})$ was dissolved with diethyl ether $(30 \mathrm{~mL})$. Sodium hydrogen carbonate $(10 \%)$ aqueous solution $(55 \mathrm{~mL})$ was added, and the mixture was stirred at room temperature for $16 \mathrm{~h}$. After separation of the basic aqueous phase from the ethereal phase, the aqueous phase was washed with diethyl ether $(2 \times 20$ 
$\mathrm{mL}$ ). The combined organic phases were dried over anhydrous sodium sulfate, filtered via the filter paper, and then concentrated using a rotary evaporator $\left(760 \mathrm{mmHg}, 40^{\circ} \mathrm{C}\right)$ to give the neutral/basic fraction I $(\sim 0.89 \mathrm{~g})$. To generate the acidic fraction, the basic aqueous phase was acidified with $50 \%$ hydrochloric acid and then the solution was extracted with diethyl ether $(3 \times 30 \mathrm{~mL})$. The combined organic phases were washed with brine $(4$ $\times 30 \mathrm{~mL}$ ) and then dried over anhydrous sodium sulfate. After filtered via the filter paper, the filtrate was concentrated to yield the acidic fraction II ( $\sim 0.03 \mathrm{~g})$ to analyze by GC-MS/O and heart-cut MDGC-MS.

\subsubsection{Flash Silica Gel Column Chromatography}

The neutral/basic fraction I ( $0.89 \mathrm{~g})$ was loaded onto a hexane-filled silica gel column $(25.3 \mathrm{~g}, 7.5 \mathrm{~cm}$ long $\times 3.4$ $\mathrm{cm}$ in diameter). The fraction was subjected to flash column chromatography. Elution was performed by $200 \mathrm{~mL}$ hexane (100\%, fraction [fr.] 1), $200 \mathrm{~mL}$ hexane/ethyl acetate $(95 / 5$, v/v, fr. 2$), 200 \mathrm{~mL}$ hexane/ethyl acetate $(80 / 20, \mathrm{v} / \mathrm{v}$, fr. 3), and finally $200 \mathrm{~mL}$ ethyl acetate $(100 \%$, fr. 4). The eluate (fr. 2$)$ was concentrated using a rotary evaporator $\left(30 \mathrm{~mm} \mathrm{Hg}, 40^{\circ} \mathrm{C}\right)$ to yield the concentrated fraction III $(\sim 0.20 \mathrm{~g})$ to analyze by GC-MS/O.

\subsubsection{Preparative Gas Chromatography (GC)}

Preparative GC was conducted using a Shimadzu GC-14B gas chromatograph connected with a thermal conductivity detector (TCD) (Shimadzu, Kyoto, Japan). The chromatograph was equipped with an InertCap WAX (polyethylene glycol) fused silica capillary column $(30 \mathrm{~m} \times 0.53 \mathrm{~mm}$ i.d.; film thickness, $1.00 \mu \mathrm{m})(\mathrm{GL}$ Sciences Inc.,Tokyo, Japan). The flow rate of the carrier gas, helium, was $2.5 \mathrm{~mL} / \mathrm{min}$. The oven temperature was programmed from $50{ }^{\circ} \mathrm{C}$ (maintained for $5 \mathrm{~min}$ ) to $230{ }^{\circ} \mathrm{C}$ (maintained for $60 \mathrm{~min}$ ) at a rising rate of $5.0^{\circ} \mathrm{C} / \mathrm{min}$. The injector and the TCD temperatures were maintained at $250{ }^{\circ} \mathrm{C}$. The exit of the chromatograph (TCD vent) was equipped with an amputated DB-WAX (polyethylene glycol) capillary column $(18 \mathrm{~cm} \times 0.53$ $\mathrm{mm}$ i.d.; film thickness, $1.00 \mu \mathrm{m})(\mathrm{J} \& \mathrm{~W}$ Scientific Inc., Tokyo, Japan), which was used to trap the eluted fractions. The samples were introduced in the direct injection mode. The separation conditions are summarized in Table 1. The hop oil was separated by repeating the procedure 10 times and 50 times to obtain the concentrated fractions IV and V, respectively, to analyze by heart-cut MDGC-MS.

Table 1. Preparative GC analysis conditions

\begin{tabular}{|c|c|c|c|}
\hline Sample & $\begin{array}{l}\text { Cutting time span } \\
\text { (min) }\end{array}$ & $\begin{array}{l}\text { Injection } \\
\text { volume }(\mu \mathrm{L})\end{array}$ & $\begin{array}{l}\text { Rate of temperature } \\
\text { increase }\left({ }^{\circ} \mathrm{C} / \mathrm{min}\right)\end{array}$ \\
\hline \multirow{2}{*}{ Hop volatile oil ${ }^{\text {a), b) }}$} & $9.0-11.0$ (for $\mathbf{C}$ ) & \multirow{2}{*}{10.0} & \multirow{2}{*}{5} \\
\hline & $15.0-17.5$ (for $\mathbf{D})$ & & \\
\hline Methyl (E)-4-methyl-3-hexenoate ${ }^{\mathrm{c})}$ & $13.0-15.5$ & 5.0 & 5 \\
\hline$S$-Methyl (E)-4-methyl-3-hexenethioate ${ }^{\mathrm{d})}$ & $19.0-20.5$ & 5.0 & 5 \\
\hline
\end{tabular}
a) Repeated 10 times for $\mathbf{C}$.
b) Repeated 50 times for $\mathbf{D}$.
c) Repeated 5 times.
d) Repeated 15 times.

\subsection{Instrumental Analysis}

\subsubsection{Gas Chromatography-Mass Spectrometry/Olfactometry (GC-MS/O)}

GC-MS/O analysis was carried out using a GC-17A gas chromatograph (Shimadzu) connected with a mass spectrometer (GCMS-QP5050, Shimadzu) and coupled with an olfactory port (OP275, GL Sciences Inc.). The chromatograph was equipped with an InertCap 1 (100\% methylpolysiloxane) fused silica capillary column (60 m $\times 0.25 \mathrm{~mm}$ i.d.; film thickness, $0.25 \mu \mathrm{m})($ GL Sciences Inc.) or with an InertCap WAX capillary column $(60 \mathrm{~m} \times$ $0.32 \mathrm{~mm}$ i.d.; film thickness, $0.25 \mu \mathrm{m}$ ) (GL Sciences Inc.), which were interfaced with both the mass spectrometer and the olfactory port via a splitter. The flow rate of the carrier gas, purified helium $(\geq 99.99995 \%)$, was $3.8 \mathrm{~mL} / \mathrm{min}$ at $70{ }^{\circ} \mathrm{C}$. The inlet system was a split/splitless mode. The inlet pressure was $170 \mathrm{kPa}$. The oven temperature was programmed from $70{ }^{\circ} \mathrm{C}$ (maintained for $5 \mathrm{~min}$ ) to $240{ }^{\circ} \mathrm{C}$ at $3{ }^{\circ} \mathrm{C} / \mathrm{min}$. The injector and the interface temperatures were maintained at $250^{\circ} \mathrm{C}$. The mass spectra in the electron impact mode were generated at $70 \mathrm{eV}$. Data were collected in full scan mode. The mass scan range was $m / z 27-300$. Olfactory detection operated during the above chromatographic separation. The temperature of the olfactory port was maintained at 
$260{ }^{\circ} \mathrm{C}$. Damp air (nitrogen/oxygen $=80 / 20$ ) was constantly pulled at a rate of $30 \mathrm{~mL} / \mathrm{min}$ via the head of the olfactory port during operation. Using the retention times of the hydrocarbons C6-C27, retention indices (RI) were calculated according to the literature (Kováts, 1958). The samples were injected under the conditions shown in Table 2. Data handling was performed using GCMS solution 1.01 Su3 (Shimadzu).

\subsubsection{Aroma Extract Dilution Analysis (AEDA) (Ullrich \& Grosch, 1987)}

The hop volatile oil was diluted stepwise with ethanol (1:1). Aliquots were analyzed by GC-MS/O equipped with an InertCap WAX capillary column. The volume of the injection was $3.0 \mu \mathrm{L}$, and the split ratio was 1:20. The flavor dilution (FD) factors $\left(2^{\mathrm{n}}\right)$ of the target compounds were estimated rom the values of the dilution degree (n).

Table 2. GC-MS/O analysis conditions

\begin{tabular}{lcc}
\hline Sample $^{\text {a) }}$ & Injection volume $(\mu \mathrm{L})$ & Injection mode (split/splitless) \\
\hline Hop volatile oil & 3.0 & $1: 10$ \\
Fraction I & 3.0 & $1: 20$ \\
Fraction II & 1.0 & $1: 20$ \\
Fraction III & 2.0 & $1: 20$ \\
Fraction IV & 2.0 & $1: 20$ \\
Fraction V & 3.0 & $1: 20$ \\
\hline
\end{tabular}

a) I: neutral/basic fraction; II: acidic fraction; III: silica gel column chromatographic fraction ( $95 / 5, \mathrm{v} / \mathrm{v})$; IV: the concentrated fraction by preparative GC $(9.0-11.0 \mathrm{~min})$; V: the concentrated fraction by preparative GC $(15.0-17.5 \mathrm{~min})$

b) Injection volume: $3.0 \mu \mathrm{L}$; injection mode: 1:20 for AEDA.

\subsubsection{Gas Chromatography-Flame Photometric Detector (GC-FPD)}

GC-FPD analysis was carried out using an Agilent $6890 \mathrm{~N}$ GC gas chromatograph connected with a flame photometric detector (FPD). The chromatographer was fitted with an InertCap Pure WAX (polyethylene glycol) fused silica capillary column $(60 \mathrm{~m} \times 0.25 \mathrm{~mm}$ i.d.; film thickness $0.25 \mu \mathrm{m})$ (GL Sciences Inc.). The flow rate of the carrier gas, purified helium ( $\geq 99.99995 \%$ ), was $0.8 \mathrm{~mL} / \mathrm{min}$. The inlet pressure was $230 \mathrm{kPa}$. The injector temperature was $250{ }^{\circ} \mathrm{C}$. The oven temperature was increased from $70{ }^{\circ} \mathrm{C}$ (maintained for $5 \mathrm{~min}$ ) to $240{ }^{\circ} \mathrm{C}$ at a rate of $3{ }^{\circ} \mathrm{C} / \mathrm{min}$. The FPD temperature was $250{ }^{\circ} \mathrm{C} ; \mathrm{H}_{2}$ flow, $75 \mathrm{~mL} / \mathrm{min}$; airflow, $100 \mathrm{~mL} / \mathrm{min}$; and the make-up flow $(\mathrm{He}), 10 \mathrm{~mL} / \mathrm{min}$. The fraction $\mathrm{V}(3.0 \mu \mathrm{L})$ was injected in a split ratio of 1:5. Data handling was performed via Chemstation software G1701DJ MSD, version C.00.01J (Agilent Technologies Japan). Using the retention times of the hydrocarbons C6-C27, retention indices (RI) were calculated according to the literature (Kováts, 1958).

\subsubsection{Heart-Cut Multidimensional Gas Chromatography-Mass Spectrometry (MDGC-MS)}

Heart-cut MDGC-MS analysis was carried out using an Agilent two-dimensional gas chromatography system, which consisted of Agilent 6890A gas chromatographs for the first (1D) and the second dimensions (2D). The 1D chromatograph was connected with a flame ionization detector (FID), while the 2D chromatograph was coupled to a mass spectrometer (Agilent 5973N MSD, Agilent Technologies Japan, Tokyo, Japan). The 1D chromatograph was connected with the 2D chromatograph via a Gerstel Cryo Trap system CTS1 (Gerstel K.K., Tokyo, Japan). The 1D chromatograph was equipped with a Gerstel multi column switching system MCS2 (Gerstel K. K.) for the heart-cutting operation. Moreover, the 1D chromatograph was equipped with a TC-WAX (polyethylene glycol) fused silica capillary column $(30 \mathrm{~m} \times 0.25 \mathrm{~mm}$ i.d.; film thickness, $0.25 \mu \mathrm{m})$ (GL Sciences Inc.), while the 2D chromatograph was fitted with an InertCap 1 capillary column $(60 \mathrm{~m} \times 0.25 \mathrm{~mm}$ i.d.; film thickness, $0.25 \mu \mathrm{m}$ ) (GL Sciences Inc.). The flow rate of the carrier gas, purified helium ( $\geq 99.99995 \%)$, was 3.8 $\mathrm{mL} / \mathrm{min}$ at $70{ }^{\circ} \mathrm{C}$. The inlet system was a split/splitless mode. The inlet pressure was $103 \mathrm{kPa}$. The injector and the transfer line temperatures were maintained at $250{ }^{\circ} \mathrm{C}$. The FID temperature was $250{ }^{\circ} \mathrm{C} ; \mathrm{H}_{2}$ flow, $60 \mathrm{~mL} / \mathrm{min}$; airflow, $100 \mathrm{~mL} / \mathrm{min}$; and the make-up flow $(\mathrm{He}), 20 \mathrm{~mL} / \mathrm{min}$. The mass spectra in the electron impact mode were generated at $70 \mathrm{eV}$ with the ion source temperature at $230^{\circ} \mathrm{C}$. Data were collected in full scan mode. The mass scan range was $m / z$ 27-300. The heart-cutting operations for the target compounds were performed under 
the conditions shown in Table 3. Data handling was performed via Chemstation software G1701CA, version C.00.00 21-Dec-1999 (Agilent Technologies Japan). Private and commercially available databases (Wiley 275 and NIST 02) were used for identification.

\subsubsection{Nuclear Magnetic Resonance}

${ }^{1} \mathrm{H}$ NMR spectra were recorded on a FT-NMR JMN-ECS 400 (400 MHz) spectrometer (JEOL Ltd., Tokyo, Japan). Chemical shifts are reported in parts per million $(\delta)$ using solvent as an internal standard $\left(\mathrm{CDCl}_{3}\right.$ at 7.26 ppm). The coupling constants, $J$, are given in hertz. Chemical patterns are indicated as follows: s, singlet; d, doublet; t, triplet; q, quartet; $\mathrm{dt}$, double triplet. ${ }^{13} \mathrm{C}$ NMR spectra were recorded on a FT-NMR JMN-ECS 400 $(100 \mathrm{MHz})$ spectrometer (JEOL Ltd.). Chemical shifts are reported in parts per million $(\delta)$ using solvent as an internal standard $\left(\mathrm{CDCl}_{3}\right.$ at $\left.77.00 \mathrm{ppm}\right)$.

\subsubsection{Infrared (IR) Spectroscopy}

IR spectra were recorded using an FTIR-8200PC spectrometer (Shimadzu). The spectrum peaksare reported as wave numbers $\left(\mathrm{cm}^{-1}\right)$. The intensities are indicated as follows: w, weak; m, medium; s, strong.

Table 3. Heart-cut MDGC-MS analysis conditions

\begin{tabular}{|c|c|c|c|c|c|c|}
\hline $\begin{array}{l}\text { Unknown } \\
\text { target } \\
\text { compound }\end{array}$ & $\begin{array}{l}\text { Heart-cutting } \\
\text { time span } \\
\text { (time) }\end{array}$ & $\begin{array}{l}\text { Injection } \\
\text { volume } \\
(\mu \mathrm{L})\end{array}$ & $\begin{array}{c}\text { Injection } \\
\text { mode } \\
\text { (split/splitless) }\end{array}$ & $\begin{array}{c}\text { 1D } \\
\text { temperature } \\
\text { program }^{\text {a) }}\end{array}$ & $\begin{array}{c}2 \mathrm{D} \\
\text { temperature } \\
\text { program }^{\mathrm{b})}\end{array}$ & $\begin{array}{l}\text { CTS } \\
\text { tempera- } \\
\text { ture }\left({ }^{\circ} \mathrm{C}\right)\end{array}$ \\
\hline A & $39.80-40.80$ & 1.0 & $1: 5$ & $\begin{array}{c}70{ }^{\circ} \mathrm{C}(5 \\
\mathrm{min}) \text { to } \\
240{ }^{\circ} \mathrm{C} \text {, at } \\
3{ }^{\circ} \mathrm{C} / \mathrm{min}\end{array}$ & $\begin{array}{c}70^{\circ} \mathrm{C}(45 \\
\min ) \text { to } \\
240^{\circ} \mathrm{C} \text {, at } \\
3{ }^{\circ} \mathrm{C} / \mathrm{min}\end{array}$ & 250 \\
\hline B & $43.20-43.80$ & 2.0 & $\begin{array}{l}\text { Splitless } \\
(1 \mathrm{~min})\end{array}$ & $\begin{array}{l}70{ }^{\circ} \mathrm{C}(5 \\
\mathrm{min}) \text { to } \\
2400^{\circ} \mathrm{C} \text {, at } \\
3{ }^{\circ} \mathrm{C} / \mathrm{min}\end{array}$ & $\begin{array}{c}70^{\circ} \mathrm{C}(45 \\
\mathrm{min}) \text { to } \\
240^{\circ} \mathrm{C} \text {, at } \\
3{ }^{\circ} \mathrm{C} / \mathrm{min}\end{array}$ & 250 \\
\hline C & $19.90-21.50$ & 1.0 & $\begin{array}{l}\text { Splitless } \\
(1 \mathrm{~min})\end{array}$ & $\begin{array}{c}70{ }^{\circ} \mathrm{C}(5 \\
\mathrm{min}) \text { to } \\
2400^{\circ} \mathrm{C} \text {, at } \\
3{ }^{\circ} \mathrm{C} / \mathrm{min}\end{array}$ & $\begin{array}{c}70{ }^{\circ} \mathrm{C}(25 \\
\min ) \text { to } \\
240^{\circ} \mathrm{C} \text {, at } \\
3{ }^{\circ} \mathrm{C} / \mathrm{min}\end{array}$ & 250 \\
\hline $\mathbf{D}^{\mathrm{c})}$ & $23.75-25.30$ & 3.0 & $1: 5$ & $\begin{array}{c}70{ }^{\circ} \mathrm{C}(5 \\
\mathrm{min}) \text { to } \\
120^{\circ} \mathrm{C}(1 \\
\mathrm{min}) \text {, at } \\
3{ }^{\circ} \mathrm{C} / \mathrm{min} \text {, } \\
\text { to } 160{ }^{\circ} \mathrm{C} \\
(1 \mathrm{~min}) \text {, at } \\
1^{\circ} \mathrm{C} / \mathrm{min} \text {, } \\
\text { to } 200^{\circ} \mathrm{C} \\
(40 \mathrm{~min}) \text {, at } \\
3{ }^{\circ} \mathrm{C} / \mathrm{min}\end{array}$ & $\begin{array}{c}80^{\circ} \mathrm{C}(10 \\
\mathrm{min}) \text { to } \\
100^{\circ} \mathrm{C}(5 \\
\mathrm{min}) \text {, at } \\
1^{\circ} \mathrm{C} / \mathrm{min} \text {, } \\
\text { to } 240{ }^{\circ} \mathrm{C} \\
(50 \mathrm{~min}) \text {, at } \\
4^{\circ} \mathrm{C} / \mathrm{min}\end{array}$ & $-20^{\mathrm{d})}$ \\
\hline
\end{tabular}

a) TC-WAX (30 m $\times 0.25 \mathrm{~mm}$ i.d.; film thickness, $0.25 \mu \mathrm{m})$.

b) InertCap $1(60 \mathrm{~m} \times 0.25 \mathrm{~mm}$ i.d.; film thickness, $0.25 \mu \mathrm{m})$.

c) Repeated 5 times.

d) Raised to $250^{\circ} \mathrm{C}$ after the repetition of heart-cutting operation.

\section{Results and Discussion}

Hallertau Perle hop was used as a standard sample according to Steinhaus et al. (2007). The hop volatile oil was extracted from the hop pellets by simultaneous steam distillation-extraction and then analyzed by GC-MS/O fitted with a polar or an apolar capillary column. The perceived sweat-like-odor active compounds are 
summarized in Table 4. The sniffing test revealed seven sweat-like-odor active compounds in Hallertau Perle hop volatile oil. Further, the AEDA result clarified the contribution of these compounds to the overall aroma at flavor dilution (FD) factors in the range of 1 to 32. Among these, 3-methylbutanoic acid and 2-methylbutanoic acid were easily identified due to their high FD factor values of 32. Interestingly, five unknown sweat-like-odor active compounds were detected. We pursued the identification of these unknown compounds.

The unknown compounds A and $\mathbf{B}$ could be perceived by GC-MS/O in the acidic fraction II, while C and D could be sniffed by GC-MS/O in both neutral/basic fraction I and the silica gel column chromatographic fraction III $(95 / 5, \mathrm{v} / \mathrm{v})$ of fraction I; however, the corresponding chromatographic peaks could not be detected (Table 4). Based on this result, A and B were predicted to be volatile acids according to the literature (Miyazato et al., 2013), while C and D were empirically predicted to be volatile ketones or esters according to the literature (Miyazato, Hashimoto, \& Hayashi, 2007).

Table 4. Sweat-like-odor active compounds identified in hop volatile oil by GC-MS/O and AEDA

\begin{tabular}{|c|c|c|c|c|c|}
\hline Compound & $\begin{array}{c}\text { RI } \\
(\text { polar })^{\mathrm{a})}\end{array}$ & $\begin{array}{c}\mathrm{RI} \\
\text { (apolar) }^{\mathrm{b})}\end{array}$ & Fraction $^{\mathrm{c})}$ & Representation of odor ${ }^{\mathrm{d})}$ & $\begin{array}{c}\text { FD } \\
\text { factor }^{e}\end{array}$ \\
\hline \multicolumn{6}{|l|}{ Acid } \\
\hline $\begin{array}{l}\text { 3-Methylbutanoic } \\
\text { acid }\end{array}$ & 1671 & 813 & II & Sweaty, rancid, cheese-like & 32 \\
\hline $\begin{array}{l}\text { 2-Methylbutanoic } \\
\text { acid }\end{array}$ & 1671 & 824 & II & Sweaty, rancid, cheese-like & 32 \\
\hline Unknown A & 1953 & 974 & II & Sweaty, urine-like, malodor in laundry & 4 \\
\hline $\begin{array}{c}\text { Unknown B } \\
\text { Others }\end{array}$ & 2052 & 1070 & II & Sweaty, urine-like, malodor in laundry & 32 \\
\hline Unknown $\mathbf{C}$ & 1367 & 1012 & I, III, IV & $\begin{array}{c}\text { Sweaty, malodor in laundry, slightly } \\
\text { fruity }\end{array}$ & 8 \\
\hline Unknown D & 1577 & 1178 & I, III, V & Sweaty, rubber & 1 \\
\hline Unknown & 1339 & - & I, III & Sweaty & 1 \\
\hline
\end{tabular}

a) InertCap WAX $(60 \mathrm{~m} \times 0.32 \mathrm{~mm}$ i.d.; film thickness, $0.25 \mu \mathrm{m})$.

b) InertCap $1(60 \mathrm{~m} \times 0.25 \mathrm{~mm}$ i.d.; film thickness, $0.25 \mu \mathrm{m})$.

c) I: neutral/basic fraction; II: acidic fraction; III: silica gel column chromatographic fraction (95/5, v/v); IV: the concentrated fraction by preparative $\mathrm{GC}(9.0-11.0 \mathrm{~min})$; $\mathrm{V}$ : the concentrated fraction by preparative GC (15.0-17.5 $\mathrm{min})$.

d) Perceived by GC-MS/O.

e) Estimated by AEDA: $2^{n}$ (n, value of dilution degree).

In addition, $\mathbf{C}$ and $\mathbf{D}$ could also be detected by GC-MS/O in the concentrated fractions IV and $\mathrm{V}$ obtained from hop volatile oil by preparative $\mathrm{GC}$; however, the corresponding chromatographic peaks could not be detected. The fraction $\mathrm{V}$ was also analyzed by gas chromatography-flame photometric detector (GC-FPD) to give the corresponding chromatographic peak (Figure 2). The result indicates that $\mathbf{D}$ has a sulfur atom.

Next, the acidic fraction II and the concentrated fractions IV and V were analyzed by heart-cut MDGC-MS. The analyses provided the corresponding chromatographic peaks and mass spectra (Figure 3-6). The identification procedure was carried out by comparing the mass spectrum, the retention indices (RIs) by a polar and an apolar column, and the sniffing odor quality by GC-MS/O with the synthesize dreference substances (Table 5). As a result, $\mathbf{A}$ and $\mathbf{B}$ were identified as 4-methyl-3-pentenoic acid and (E)-4-methyl-3-hexenoic acid, respectively, while $\mathbf{C}$ and $\mathbf{D}$ were determined to be methyl (E)-4-methyl-3-hexenoate and $S$-methyl (E)-4-methyl-3-hexenethioate, respectively (Figure 7).

4-Methyl-3-pentenoic acid has been described in hop essential oil (Sandra \& Verzele, 1975; Tressl, Friese, Fendesack, \& Köppler, 1978a; Tressl \& Friese, 1978b). In our study, we determined that 4-methyl-3-pentenoic acid could be responsible for the sweat-like odor in hops. 4-Methyl-3-pentenoic acid, along with 
2-methylpropanoic acid, 3-methylbutanoic acid, and 2-methylbutanoic acid, is generated via the oxidative degradation of certain hop acids (Sandra et al., 1975). We also observed the generation of 4-methyl-3-pentenoic acid from isohumulone via heat-promoted oxidative degradation (data not shown).

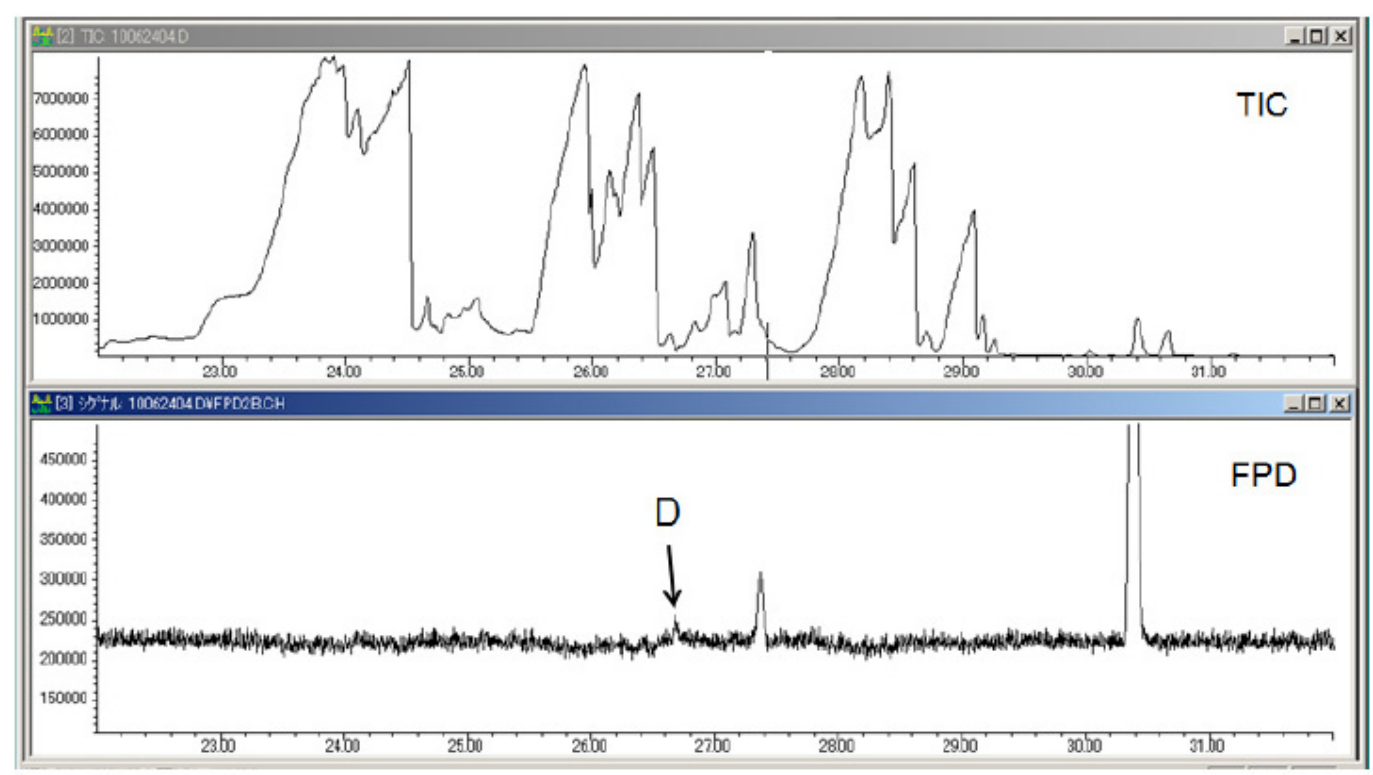

Figure 2. Detection of unknown compound $\mathbf{D}$ in fraction Vby GC-FPD

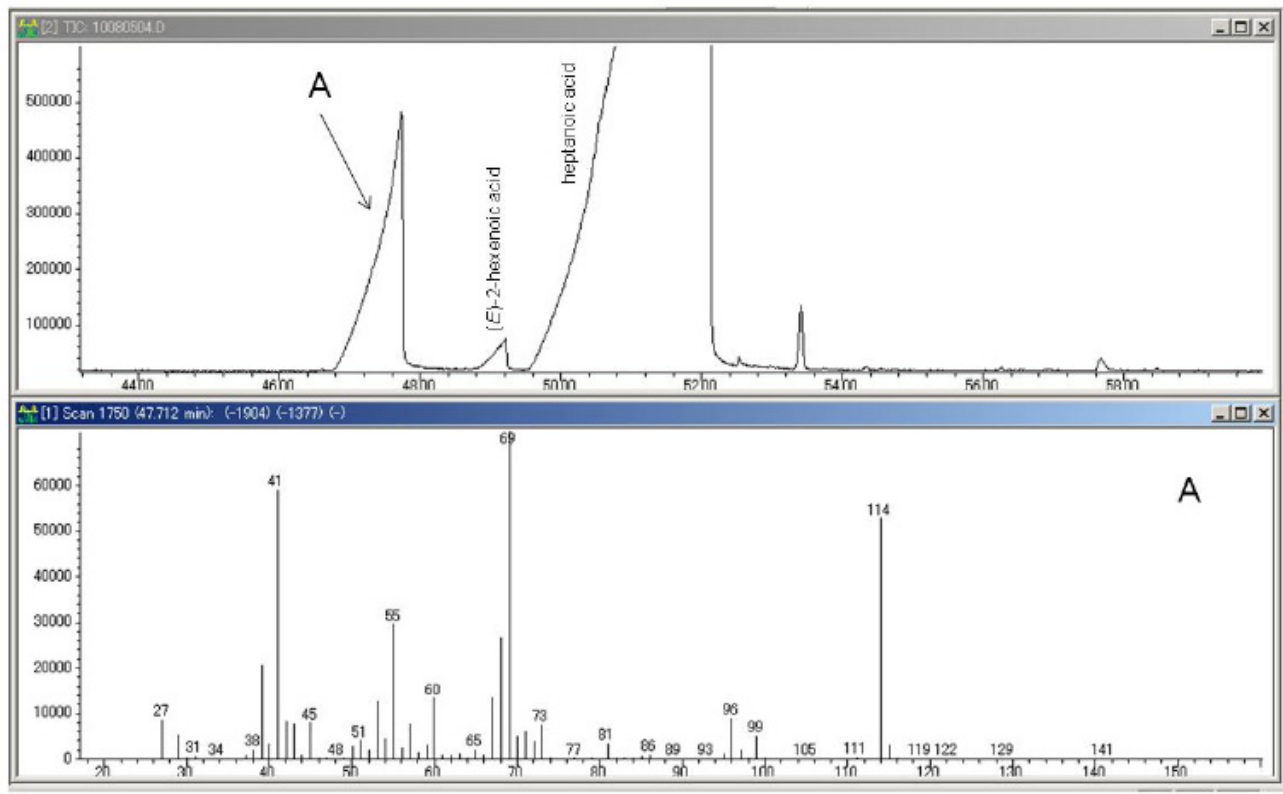

Figure 3. Enlarged images of the total ion chromatogram (2D) (upper panel) and the mass spectrum (lower panel) of unknown compound $\mathbf{A}$ as analyzed by heart-cut MDGC-MS 


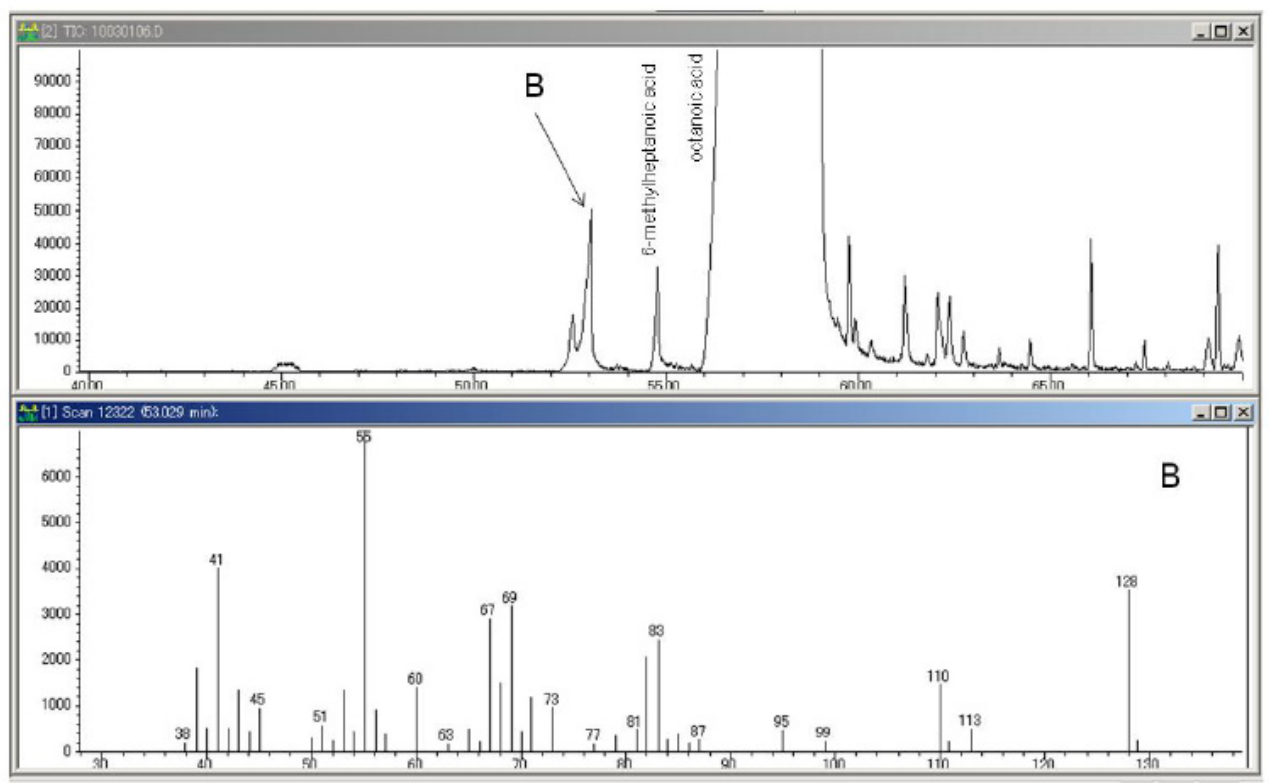

Figure 4. Enlarged images of the total ion chromatogram (2D) (upper panel) and the mass spectrum (lower panel) of unknown compound $\mathbf{B}$ as analyzed by heart-cut MDGC-MS

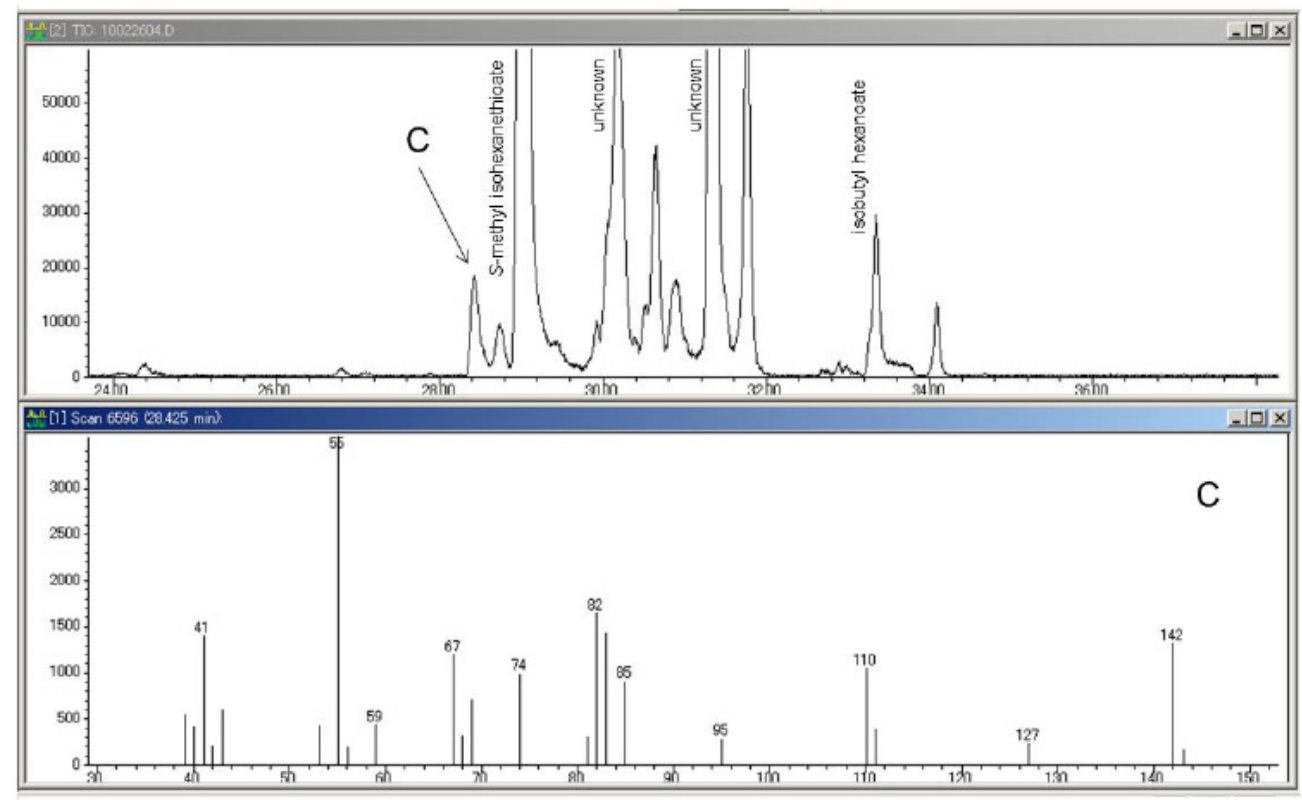

Figure 5. Enlarged images of the total ion chromatogram (2D) (upper panel) and the mass spectrum (lower panel) of unknown compound $\mathbf{C}$ as analyzed by heart-cut MDGC-MS 


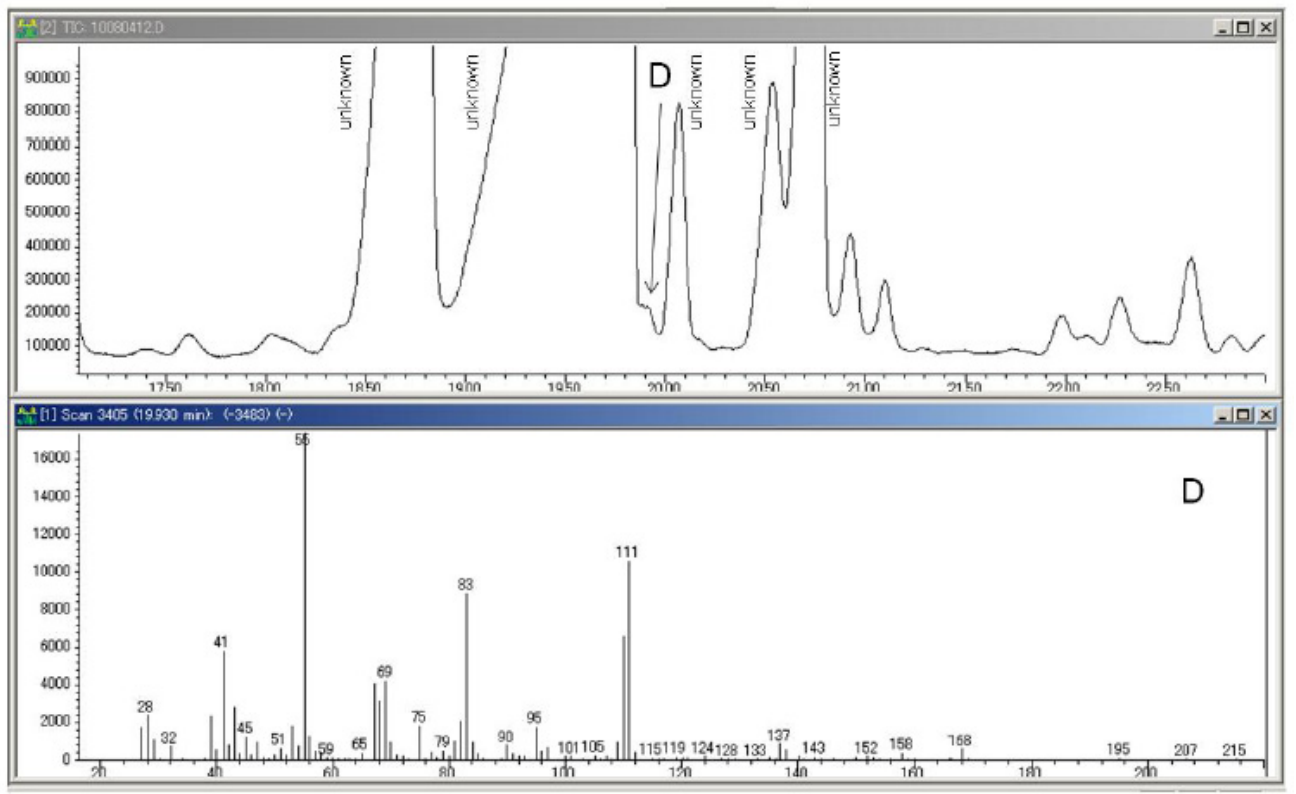

Figure 6. Enlarged images of the total ion chromatogram (2D) (upper panel) and the mass spectrum (lower panel) of unknown compound $\mathbf{D}$ as analyzed by heart-cut MDGC-MS

A<smiles>CC(C)=CCC(=O)O</smiles>

C<smiles>CC/C(C)=C/CC(=O)OC</smiles>

B<smiles>CC/C(C)=C/CC(=O)O</smiles>

D<smiles>CC/C(C)=C/CC(C)=O</smiles>

Figure 7. Thechemical structures of the sweat-like-odor active compounds identified in HallertauPerle hop volatile oil: A, 4-methyl-3-pentenoic acid; B, $(E)$-4-methyl-3-hexenoic acid; $\mathbf{C}$, methyl

(E)-4-methyl-3-hexenoate; D, $S$-methyl (E)-4-methyl-3-hexenethioate 
Table 5. Characteristics of reference substances used for unknown target compound identification

\begin{tabular}{|c|c|c|c|c|c|}
\hline $\begin{array}{l}\text { Unknown } \\
\text { target } \\
\text { compound }\end{array}$ & $\begin{array}{l}\text { Reference } \\
\text { substance }\end{array}$ & Mass spectrum $^{\text {a) }}$ & $\begin{array}{l}\text { RI } \\
(\text { polar) }\end{array}$ & $\begin{array}{l}\text { RI } \\
(\text { apolar) }\end{array}$ & $\begin{array}{l}\text { Odor } \\
\text { quality }{ }^{\mathrm{d})}\end{array}$ \\
\hline $\mathbf{A}$ & $\begin{array}{l}\text { 4-Methyl-3- } \\
\text { pentenoic acid }\end{array}$ & $\begin{array}{l}39(28), 41(100), 42(10), 43(12), 45 \\
(15), 53(14), 55(12), 56(14), 67(12), \\
68(16), 69(90), 114\left(\mathrm{M}^{+}, 38\right) .\end{array}$ & 1951 & 974 & $\begin{array}{l}\text { Sweaty, } \\
\text { urine-like, } \\
\text { malodor in } \\
\text { laundry }\end{array}$ \\
\hline B & $\begin{array}{l}(E)-4-M e t h y l-3- \\
\text { hexenoic acid }\end{array}$ & $\begin{array}{l}27(38), 29(21), 39(36), 41(69), 43 \\
(19), 45(31), 51(10), 53(19), 55(100), \\
56(11), 67(31), 68(13), 69(33), 71 \\
(11), 82(20), 83(22), 110(9), 128\left(\mathrm{M}^{+},\right. \\
29) .\end{array}$ & 2052 & 1070 & $\begin{array}{l}\text { Sweaty, } \\
\text { urine-like, } \\
\text { malodor in } \\
\text { laundry }\end{array}$ \\
\hline C & $\begin{array}{l}\text { Methyl } \\
(E)-4-\text { methyl-3- } \\
\text { hexenoate }\end{array}$ & $\begin{array}{l}39(14), 41(32), 43(10), 53(10), 55 \\
(100), 59(11), 67(31), 68(10), 69(17), \\
74(28), 82(51), 83(50), 85(7), 95(7), \\
110(35), 127(7), 142\left(\mathrm{M}^{+}, 45\right) .\end{array}$ & 1368 & 1012 & $\begin{array}{l}\text { Sweaty, } \\
\text { malodor } \\
\text { laundry, } \\
\text { fruity }\end{array}$ \\
\hline D & $\begin{array}{l}S \text {-Methyl } \\
(E) \text {-4-methyl-3- } \\
\text { hexenethioate }\end{array}$ & $\begin{array}{l}39(11), 41(28), 55(100), 67(11), 75 \\
(11), 82(12), 83(64), 110(41), 111 \\
(44), 158\left(\mathrm{M}^{+}, 2\right) .\end{array}$ & 1578 & 1176 & $\begin{array}{l}\text { Sweaty, } \\
\text { rubber }\end{array}$ \\
\hline
\end{tabular}

a) EI, $70 \mathrm{eV}, m / z$ (relative intensity).

b) InertCap WAX $(60 \mathrm{~m} \times 0.32 \mathrm{~mm}$ i.d.;film thickness, $0.25 \mu \mathrm{m})$.

c) InertCap $1(60 \mathrm{~m} \times 0.25 \mathrm{~mm}$ i.d.;film thickness, $0.25 \mu \mathrm{m})$.

d) Perceived by GC-MS/O.

(E)-4-Methyl-3-hexenoic acid was identified for the first time in hops. Very recently, $(E)$-4-methyl-3-hexenoic acid has been determined to be an odor-active compound in some natural sources, such as yuzu (Miyazato et al., 2013) and kabosu (Tomiyama, Aoki, Oikawa, Sakurai, Kasahara, \& Kawakami, 2012). Further, Takeuchi, Hasegawa, Ishida, and Kashiwagi (2012) have reported (E)-4-methyl-3-hexenoic acid as the key odorous component responsible for the malodor in laundry. In our study, among the seven sweat-like-odor active compounds, $(E)$-4-methyl-3-hexenoic acid, along with 3-methylbutanoic acid and 2-methylbutanoic acid, has a high FD factor value of 32. Therefore, $(E)$-4-methyl-3-hexenoic acid was found to be the key odorous component responsible for the sweat-like odor in hops.

The generation pathway of (E)-4-methyl-3-hexenoic acid found in hops remains unclear. (E)-4-Methyl-3-hexenoic acid is formed from myrcene (Narushima, Omori, \& Minoda, 1982; Mikami, 1988) or linalool (Mizutani, Hayashi, Ueda, \& Tatsumi, 1971) via enzyme-catalyzed oxidative degradation. In yuzu (Miyazato et al., 2013), the (E)-isomer is predominant and, in contrast, the (Z)-isomer was not detected. Additionally, in hops, the (Z)-isomer was not detected, which is similar to yuzu. Therefore, similar to yuzu, the (E)-4-methyl-3-hexenoic acid present in hops, may originate from myrcene and/or linalool because hop volatile oil contains myrcene and linalool as major volatile components (Nijssen et al., 2013). Further investigation is needed to clarify the formation of $(E)$-4-methyl-3-hexenoic acid in hops.

Although a great number of esters and thioesters have been described in hop volatile oil (Nijssen et al., 2013), in this study, methyl $(E)$-4-methyl-3-hexenoate and $S$-methyl $(E)$-4-methyl-3-hexenethioate were identified for the first time. Interestingly, these compounds have a sweat-like odor. This is the first study that indicates there are odorous components beyond volatile carboxylic acids responsible for the sweat-like odor of hops.

The biological synthesis of a great number of methyl esters present in hops remains unclear. Supriyadi, Suzuki, Wu, Tomita, Fujita, and Watanabe (2003) first reported the biogenesis of methyl esters in snake fruit. The authors demonstrated that a methyl ester is generated via the enzymatic esterification of an acid (acetyl-CoA) with methanol that is stemmed from methyl pectin via enzymatic degradation. Methyl (E)-4-methyl-3-hexenoate present in hops could be generated in the same way.

In addition, a majority of the methyl thioesters present in hops are biosynthesized via thioesterification of the 
corresponding acids with methyl mercaptan originating from L-methionine (Lermusieau \& Collin, 2003). Based on this finding, $S$-methyl $(E)$-4-methyl-3-hexenethioate may be generated in the same way.

$S$-Methylthiomethyl ester is present uniquely in hop volatile oil (Moir, Gallacher, Hobkirk, Seaton, \& Suggett, 1980; Lermusieau et al., 2003). However, $S$-methylthiomethyl (E)-4-methyl-3-hexenethioate, which has a rubber odor, was not present in hops.

The odorous compound detected at RI (InertCap WAX) $=1339$ remains unknown (Table 4). This compound could be detected in the same fraction I and III as methyl $(E)$-4-methyl-3-hexenoate and $S$-methyl (E)-4-methyl-3-hexenethioate. Subsequently, we determined that this compound is not a volatile carboxylic acid. Lermusieau et al. (2001) have stressed that 3-methylthiopropanal or $S$-methyl butanethioate, along with one unidentified compound, are the sweat-like odorous compounds in Challenger hop pellet volatile oil. In addition, Steinhaus et al. $(2000,2007)$ have not reported the sweat-like-odor active components in hop volatile oil except for butanoic acid, 3-methylbutanoic acid, and pentanoic acid, which in general have a sweat-like odor. This is the first study that demonstrably elucidated seven odorous components responsible for the sweat-like odor in hop volatile oil.

We did not examine whether the novel sweat-like-odor active compounds contribute to the aroma of hop-containing beer. The volatile compounds found in hops are transferred to beer, and these derived-volatile components have an influence on the aroma of beer (Sandra et al., 1975; Tressl, Friese, Fendesack, \& Köppler, 1978c; Kishimoto, Wanikawa, Kono, \& Shibata, 2006; Takoi et al., 2009). Sandra et al. (1975) have stressed the contribution of 3-methylbutanoic acid, 2-methylbutanoic acid, and 4-methyl-3-pentenoic acid to the flavor of beer because these compounds in hop-containing beer are present in higher concentration than those in hop-free beer. In addition, Steinhaus et al. (2007) have emphasized that the hop-derived esters do not contribute to the aroma of beer, most likely because these esters are decreased via hydrolysis during the kettle hop boiling in the brewing process, according to Tressl et al. (1978a). Thioesters also tend to be hydrolyzed. Based on these literature findings, we expect that 4-methyl-3-pentenoic acid and (E)-4-methyl-3-hexenoic acid, which were identified in this study, proceed with beer in the production and contribute to the beer overall aroma.

\section{Conclusion}

In this study, it was demonstrated that the seven odorants, such as 3-methylbutanoic acid, 2-methylbutanoic acid, 4-methyl-3-pentenoic acid, (E)-4-methyl-3-hexenoic acid, methyl (E)-4-methyl-3-hexenoate, $S$-methyl (E)-4-methyl-3-hexenethioate, and an unknown compound, are responsible for sweat-like odor in Hallertau Perle hop volatile oil. Among these, $(E)$-4-methyl-3-hexenoic acid, methyl $(E)$-4-methyl-3-hexenoate, and $S$-methyl (E)-4-methyl-3-hexenethioate were first identified.

\section{Acknowledgments}

We would like to thank Prof. Dr. Ilhyong Ryu for assistance with the JEOL FT-NMR JMN-ECS400 spectrometer located at Osaka Prefecture University. We extend our sincere gratitude to Dr. Hiromu Kameoka for the close support and encouragement.

\section{References}

Eyres, G., \& Dufour, J. -P. (2009). Hop essential oil: Analysis, chemical composition and odor characteristics. In V. R. Preedy (Ed.), Beer in health and disease prevention (Chapter 22, pp. 239-254). London, UK: Academic Press-Elsevier Inc.

Furukawa, J., Murakami, A., \& Ichii, T. (2012). Preliminary results of a genetic approach for comparing hop aroma compounds. Institute of Brewing \& Distilling $32^{\text {nd }}$ Convention Proceedings, Melbourne, Australia. Retrieved from http://www.ibdasiapac.com.au/asia-pacific-activities/convention-proceedings/2012/results.html

Khan, J. A., Gijs, L., Berger, C., Martin, N., Piraprez, G., Spinnler, H. E., ... Collin, S. (1999). Combinatorial approach to flavor analysis. 1. Preparation and characterization of a $S$-methyl thioester library. Journal of Agricultural and Food Chemistry, 47, 3269-3273. http://dx.doi.org/10.1021/jf9902043

Kishimoto, T., Wanikawa, A., Kono, K., \& Shibata, K. (2006). Comparison of the odor-active compounds in unhopped beer and beers hopped with different hop varieties. Journal of Agricultural and Food Chemistry, 54, 8855-8861. http://dx.doi.org/10.1021/jf061342c

Kováts, E. (1958). Gas-chromatographische charakterisierung organischer verbindungen. Teil 1: Retentionsindices aliphatischer halogenide, alkohole, aldehyde und ketone. Helvetica Chimica Acta, 41, 1915-1932. http://dx.doi.org/10.1002/hlca.19580410703

Lermusieau, G., Bulens, M., \& Collin, S. (2001). Use of GC-olfactometry to identify the hop aromatic 
compounds in beer. Journal of Agricultural and Food Chemistry, 49, 3867-3874. http://dx.doi.org/10.1021/jf0101509

Lermusieau, G., \& Collin, S. (2003). Volatile sulfur compounds in hops and residual concentration in beer-A review. Journal of the American Society of Brewing Chemistry, 61, 109-113. http://dx.doi.org/10.1094/ASBCJ-61-0109

Likens, S. T., \& Nickerson, G. B. (1964). Detection of certain hop oil constituents in brewing products. American Society of Brewing Chemists Proceedings. Annual Meeting (Saint-Paul), 5-13.

Mikami, Y. (1988). Microbial conversion of terpenoids. In S. Harding (Ed.), Biotechnology and Genetic Engineering Reviews (Vol. 6, pp. 271-320). Wimborne, UK: Intercept Ltd. Retrieved from http://www.nottingham.ac.uk/ncmh/BGER/volume-6.html

Mikolajczak, K. L., \& Smith Jr., C. R. (1978). Synthesis of harringtonine, a Cephalotaxus antitumor alkaloid. The Journal of Organic Chemistry, 43, 4762-4765. http://dx.doi.org/10.1021/jo00419a012

Miyazato, H., Hashimoto, S., \& Hayashi, S. (2007). Research on new key odorants in yuzu peel oil (Citrus junos Tanaka).The $51^{\text {st }}$ Symposium on the Chemistry of Terpenes, Essential Oils, and Aromatics, 79-81.

Miyazato, H., Hashimoto, S., \& Hayashi, S. (2013). First identification of the odour-active unsaturated aliphatic acid (E)-4-methyl-3-hexenoic acid in yuzu (Citrus junos Sieb. ex Tanaka). Flavour and Fragrance Journal, 28, 62-69. http://dx.doi.org/10.1002/ffj.3128

Mizutani, S., Hayashi, T., Ueda, H., \& Tatsumi, C. (1971). Microbiological conversion of terpenes part IX. Conversion of linalool. Nippon Nogei Kagaku Kaishi, 45, 368-373. Retrieved from https://www.jstage.jst.go.jp/article/nogeikagaku1924/45/8/45_8_368/_pdf

Moir, M., Gallacher, I. M., Hobkirk, J., Seaton, J. C., \& Suggett, A. (1980). Methylthiomethyl 2-methylbutanethiolate in essential oil of hop. Tetrahedron Letters, 21, 1085-1086. http://dx.doi.org/10.1016/S0040-4039(00)78846-0

Narushima, H., Omori, T., \& Minoda, Y. (1982). Microbial oxidation of $\beta$-myrcene. In C. Vezina \& K. Singh (Eds.), Advances in Biotechnology (Vol. 3, pp. 525-531). Oxford, England: Pergamon Press.

Nijssen, L. M.,Ingen-Visscher, C. A., \& Donders, J. J. H.VCF Volatile Compounds in Food database, Version 13.2 (1963-2012), TNO Triskelion, Zeist (The Netherlands). Retrieved fromhttp://www.vcf-online.nl/VcfHome.cfm

Sandra, F., \& Verzele, M. (1975). Contribution of hop-derived compounds to beer aroma. Proceedings of the congress-European brewery convention, 15, 107-122.

Steinhaus, M., \& Schieberle, P. (2000). Comparison of the most odor-active compounds in fresh and dried hop cones (Humulus lupulus L. variety Spalter Select) based on GC-olfactometry and odor dilution techniques. Journal of Agricultural and Food Chemistry, 48, 1776-1783. http://dx.doi.org/10.1021/jf9905141

Steinhaus, M., Wilhelm, W., \& Schieberle, P. (2007). Comparison of the most odour-active volatiles in different hop varieties by application of a comparative aroma extract dilution analysis. European Food Research and Technology, 226, 45-55. http://dx.doi.org/10.1007/s00217-006-0507-6

Supriyadi, S., Suzuki, M., Wu, S., Tomita, N., Fujita, A., \& Watanabe, N. (2003). Biogenesis of volatile methyl esters in snake fruit (Salaccaedulis, Reinw) cv. Pondoh.Bioscience, Biotechnology, and Biochemistry, 67, 1267-1271. http://dx.doi.org/10.1271/bbb.67.1267

Takeuchi, K., Hasegawa, Y., Ishida, H., \& Kashiwagi, M. (2012). Identification of novel malodour compounds in laundry. Flavour and Fragrance Journal, 27, 89-94. http://dx.doi.org/10.1002/ffj.2088

Takoi, K., Degueil, M., Shinkaruk, S., Thibon, C., Maeda, K., Ito, K., Bentetau, B., Dubourdieu, D., \& Tominaga, T. (2009). Identification and characteristics of new volatile thiols derived from the hop (Humulus luplus L.) cultivar Nelson Sauvin. Journal of Agricultural and Food Chemistry, 57, 2493-2502. http://dx.doi.org/10.1021/jf8034622

Tomiyama, K., Aoki, H., Oikawa, T., Sakurai, K., Kasahara, Y., \& Kawakami, Y. (2012). Characteristic volatile components of Japanese sour citrus fruits: yuzu, sudachi, and kabosu. Flavour and Fragrance Journal, 27, 341-355. http://dx.doi.org/10.1002/ffj.3104

Tressl, R., Friese, L., Fendesack, F., \& Köppler, H. (1978a). Studies of the volatile composition of hops during storage. Journal of Agricultural and Food Chemistry, 26, 1426-1430. http://dx.doi.org/10.1021/jf60220a036 
Tressl, R., \& Friese, L. (1978b). Gaschromatographisch-massenspectrometrischeuntersuchung der aromastoffe von Spalterhopfen. Zeitschriftfür Lebensmittel-Untersuchung und -Forschung A, 166, 350-354. http://dx.doi.org/10.1007/BF01181504

Tressl, R., Friese, L., Fendesack, F., \& Köppler, H. (1978c). Gas chromatographic-mass spectrometric investigation of hop aroma constituents in beer. Journal of Agricultural and Food Chemistry, 26, 1422-1426. http://dx.doi.org/10.1021/jf60220a037

Ullrich, F., \& Grosch W. (1987). Identification of the most intense volatile flavour compounds formed during autoxidation of linoleic acid. ZeitschriftfürLebensmittel-Untersuchung und -Forschung A, 184, $277-282$. http://dx.doi.org/10.1007/BF01027663

\section{Copyrights}

Copyright for this article is retained by the author(s), with first publication rights granted to the journal.

This is an open-access article distributed under the terms and conditions of the Creative Commons Attribution license (http://creativecommons.org/licenses/by/3.0/). 